\title{
Factors affecting cure when treating bovine clinical mastitis with cephalosporin-based intramammary preparations
}

\author{
A. J. Bradley* ${ }^{*}$ and M. J. Green $\ddagger$ \\ *University of Bristol, Division of Farm Animal Science, School of Veterinary Science, Langford House, Langford, Bristol, BS40 5DU, United \\ Kingdom \\ †Quality Milk Management Services Ltd., Unit 1, Lodge Hill Industrial Park, Station Road, Westbury-sub-Mendip, Nr Wells, Somerset, \\ BA5 1EY, United Kingdom \\ ‡University of Nottingham, School of Veterinary Medicine and Science, Sutton Bonington Campus, Sutton Bonington, Leicestershire, \\ LE12 5RD, United Kingdom
}

\section{ABSTRACT}

Data were collated for an independent scientific analysis from 2 international, multicenter studies that had compared the efficacy of 3 different cephalosporincontaining intramammary preparations in the treatment of clinical mastitis in dairy cattle [cefalexin (first generation) in combination with kanamycin; cefquinome (fourth generation); and cefoperazone (third generation)]. Quarters were assessed using standard bacteriological techniques before treatment and at 16 and 25 $\mathrm{d}$ posttreatment. Additional data were also available on individual cows and study farms, including parity, breed, and cow somatic cell count histories, herd bulk milk somatic cell counts, and farm management regimens. Sufficient data for analysis were available from a total of 491 cases on 192 farms in 3 countries (United Kingdom, France, and Germany) with up to 16 cases being recruited from any one farm. Clinical cases were of diverse etiology, representing both contagious and environmental pathogens. Univariable analysis demonstrated that quarters in the cefalexin + kanamycin and cefquinome treatment groups were not significantly different from each other, but were both significantly more likely to be pathogen free posttreatment than quarters in the cefoperazone group. Multivariable analysis was undertaken using conventional random effects models. Two models were built, with the first incorporating only information available to the practitioner at the time of treatment and the second including all information collected during the study. These models indicated that country, pretreatment rectal temperature (above-normal temperature associated with an increased chance of being pathogen free posttreatment), individual cow somatic cell count (increased somatic cell count associated with a decreased chance of being pathogen free

Received June 30, 2008.

Accepted December 8, 2008.

${ }^{1}$ Corresponding author: A.J.Bradley@bristol.ac.uk posttreatment), and pathogen (Staphylococcus aureus isolation associated with a decreased chance of being pathogen free posttreatment) were useful predictors of pathogen free status; parity, yield, bulk milk somatic cell counts, and other farm management factors were not. The importance of country in the analysis demonstrates the need to generate local data when assessing treatment regimens. In addition, these results suggest that the factors important in predicting the outcome of treatment of clinical mastitis cases may be dissimilar to those reported to affect the likelihood of cure when treating subclinical intramammary infections.

Key words: clinical mastitis, treatment, risk factor, cephalosporin

\section{INTRODUCTION}

Clinical mastitis is defined as mastitis associated with visible changes in milk, as opposed to subclinical mastitis, when there are no visible changes and IMI is associated only with changes in secretion variables such as an increase in the SCC. The exact reasons why a cow develops clinical or subclinical mastitis after intramammary challenge are not well understood, but it is likely to be influenced by the pathogen involved (both species and strain) as well as the immune status of the cow (Sordillo et al., 1997). There are several scenarios surrounding how a cow develops clinical mastitis and the ensuing sequelae; clinical mastitis may develop immediately after intramammary challenge or, alternatively, after a sometimes protracted period of subclinical infection (Bradley and Green, 2001a; Zadoks et al., 2003). After clinical mastitis and the resolution of clinical signs, a quarter may return to the uninfected state (experiencing a bacteriological cure) or persistent IMI may occur, after which there may or may not be recrudescence of clinical disease (Bradley and Green, 2001a; Zadoks et al., 2003).

In excess of 150 different pathogens have been associated with bovine mastitis (Watts, 1988). The etiology of clinical mastitis is diverse and varies significantly in- 
ternationally as well as within regions within countries and between farms, and shows significant variation over time and between seasons on individual units (Bradley and Green, 2001b; Bradley et al., 2007). This variation in etiology presents several challenges to the producer and veterinarian alike, first because there may be a need to adapt control measures over time, but also because, when presented with a case of clinical mastitis, it is not possible to make a reliable diagnosis of the likely cause in the absence of additional laboratory tests, such as microbiology (White et al., 1986). This inability to identify the causative agent reliably at the time of clinical presentation is one of the rationales behind the development of broad-spectrum intramammary tubes, based on either the use of broad-spectrum antibiotics or the use of antibiotic combinations to cover a broad range of the possible pathogens involved.

As outlined above, the rationale for development of polypharmaceutical intramammary products is to offer broad-spectrum protection in a preparation that persists sufficiently in the udder to effect a cure while not resulting in unacceptably long antibiotic residue withholding times. Recently, there has been increasing interest in the interaction between different antibiotics when used in combination (Monzon et al., 2001). This interaction can occur at several levels, from antagonism at one extreme through no interaction, to synergism at the other (Odds, 2003). These interactions are becoming more clearly understood and are increasingly being exploited in both human and veterinary medicine.

Several intramammary products for the treatment of IMI in dairy cattle contain cephalosporins, most commonly as a single product (e.g., cefquinome, Cephaguard LC Intramammary, Intervet UK Ltd., Milton Keynes, UK; cefoprazone, Peracef Intramammary Suspension, Pfizer GmbH, Karlsruhe, Germany), but also in combination (cefalexin and kanamycin, Ubrolexin, Boehringer Ingelheim Animal Health, Ingelheim, Germany). The cephalosporins are semisynthetic antibiotics derived from cephalosporin $\mathrm{C}$ (produced by Cephalosporium acremonium). There are currently 4 generations of cephalosporins, which vary from the narrow-spectrum first generation through the expanded-spectrum second generation, the broad-spectrum third generation, and the extended-spectrum fourth-generation products (Hornish and Kotarski, 2002), with all generations being used in veterinary medicinal products. As their descriptions suggest, as one moves through the generations, the cephalosporins become more broad spectrum in their activity, with first-generation products having a gram-positive spectrum with limited gram-negative activity and fourth-generation products having a very wide spectrum of activity (Hornish and Kotarski, 2002).
When using a first-generation cephalosporin in an intramammary preparation, there is a strong rationale for combining it with an additional antibiotic to extend the spectrum of the product. One such example is the product Ubrolexin (Boehringer Ingelheim Animal Health), which is one of the products included in the analysis presented in this paper. In this instance, cefalexin is administered in combination with the aminoglycoside antibiotic kanamycin, thereby broadening the spectrum of activity to more thoroughly encompass gram-negative organisms. Interestingly, recent research has demonstrated synergy against several key mastitis pathogens when these 2 antibiotics are combined, offering a potential for increased efficacy compared with using either of the antibiotics alone (Ganiere and Denuault, 2009).

With the exception of papers reporting clinical trials, and in contrast to the treatment of subclinical mastitis, very little has been published in the peer-reviewed literature about factors affecting the likely outcome of treatment of clinical mastitis cases. Although differences in cure rates have been demonstrated between different intramammary products (Deluyker et al., 1999), the only other major factors to have been investigated and identified as being important in determining the outcome of treatment of clinical cases are the speed with which treatment is initiated and the duration of treatment, with more rapid identification and initiation of treatment (Hillerton and Semmens, 1999) and increased duration of treatment both being associated with improved cure rates (Oliver et al., 2004; Deluyker et al., 2005).

In contrast, the factors affecting the likely outcome of treatment of subclinical mastitis are much better understood and have been more thoroughly investigated. It is well established that significant differences in cure rate are associated with farm factors such as bulk milk SCC (BMSCC), the pathogen involved, the duration of infection, the duration of treatment, the number of quarters affected (Sol et al., 1994, 1997; Deluyker et al., 1999), the parity of the affected animal, and the timing of treatment in the lactation cycle, with enhanced cure rates achieved in the dry period compared with lactation (Bradley et al., 2003).

There are several ways of assessing the outcome of treatment of cases of clinical mastitis, including the simple assessment of the resolution of clinical signs (treatment success as perceived by the farmer), the indirect assessment of response to treatment by measurement of posttreatment SCC, and the "gold standard" approach of serial bacteriological culture. At a species-specific level, it is possible to calculate cure rates based on the failure to retrieve the causal pathogen in posttreatment samples, although this approach has 2 possible flaws. 
First, it precludes the ability to assess the outcome in cases that were culture negative in the pretreatment sample, and second, because although it allows an assessment with respect to a specific pathogen, it tells the investigator little about the overall prognostic outcome and therefore likely survival of the animal in the herd longer term. Therefore, as well as measuring pathogen-specific outcomes (cure rates), an assessment based on the likelihood of a quarter being pathogen free posttreatment provides a biologically useful and robust assessment of the outcome of treatment, which may better reflect the long-term survival of the animal in the herd.

The primary objective of this study was to investigate factors important both in determining and in predicting the outcome of treatment of clinical mastitis, in this case with intramammary products containing cephalosporins. A secondary aim was to inform the expectations of the practitioner with respect to the outcome of treatment of clinical mastitis.

\section{MATERIALS AND METHODS}

Data were collated from 2 multicenter international efficacy studies that compared the use of different cephalosporin-containing intramammary products in the treatment of bovine clinical mastitis occurring during lactation. Both studies followed the same protocol (with the exception of treatment regimens) and were conducted to the guidelines for Good Clinical practice as drawn up under the International Cooperation on Harmonisation of Technical Requirements for Registration of Veterinary Medicinal Products (http://www. emea.europa.eu/pdfs/vet/vich/059598en.pdf) between April 2004 and January 2005. Study A was conducted in the United Kingdom and France, and study B was conducted in the United Kingdom and Germany. A product containing the first-generation cephalosporin cefalexin, in combination with kanamycin (CEFK; Ubrolexin, Boehringer Ingelheim Animal Health) was used in both studies and was compared with a fourthgeneration cephalosporin, cefquinome (CEFQ; Cephaguard/Cobactan, Intervet UK Ltd.) in study A and with a third-generation cephalosporin, cefoperazone (CEFP; Peracef, Pfizer GmbH; group 3) in study B. All data from both studies were made available to the authors for the purpose of the analyses presented in this paper.

\section{Herd Details}

Cows experiencing clinical mastitis, as identified by a trained herdsperson and subsequently confirmed by a veterinary surgeon, were recruited to the studies from
192 commercial dairy farms in 3 countries, with up to 16 cases being recruited from any one farm (maximum: 16; minimum: 1; mean: 2.56; median: 2). Herd size varied from 2 to 480 cows in milk. All animals were managed according to normal husbandry regimens for each farm, and all herds followed a twice-daily milking regimen. In the 3 mo before the study, the geometric mean BMSCC on the farms from which cows were recruited was 211,000 cells/mL (range 48,000 and 590,000 cells/ $\mathrm{mL})$. There were diverse management and husbandry practices across the study sites, encompassing both cubicle and loose yard systems and a variety of feeding systems. Foremilking was practiced by $84.7 \%$ of herds. No form of premilking teat preparation regimen was practiced in $33.4 \%$ of herds. Postmilking teat disinfection was practiced by $77.2 \%$ of farms.

\section{Inclusion and Exclusion Criteria}

Clinical mastitis was characterized by signs of inflammation in the affected quarter (pain, swelling, heat, or redness) or by altered secretion (clots, flakes, watery appearance, or discoloration), or both. With the exception of an abnormal rectal temperature, cows exhibiting systemic signs or cows considered by a veterinary surgeon to need additional systemic therapy were excluded from the studies. Animals affected in more than one mammary gland quarter were also excluded. In addition, cows within $5 \mathrm{~d}$ postcalving, within $30 \mathrm{~d}$ of drying off, yielding less than $5 \mathrm{~L}$ of milk/day, with visible signs of teat damage, suffering concurrent disease, or that had been treated with antimicrobial or antiinflammatory products within the previous $30 \mathrm{~d}$ were not recruited to the studies. All cases meeting the defined criteria were included in the analysis.

\section{Clinical Examination and Follow-Up}

Cows selected for inclusion in the study were clinically examined, by a veterinary surgeon, before the first treatment on d 0 and again on d 2, 3, and $16( \pm 1)$. On each occasion, in addition to a general examination, both the affected quarter and its secretion were assessed and scored using a system that graded the severity of signs of inflammation and changes in secretion appearance, respectively. The examination on d 0 also served to ensure that the recruited animals or quarters met the study inclusion criteria.

\section{Treatment Allocation and Administration}

Investigators, laboratory personnel, and farmers were blinded to treatment allocation. The products were supplied in overlabeled packaging in the commercially 
Table 1. Summary of intramammary treatment regimens ${ }^{1}$

\begin{tabular}{|c|c|c|c|c|}
\hline Group & Treatment & $\begin{array}{l}\text { Treatment } \\
\text { frequency }\end{array}$ & Treatment schedule & $\begin{array}{c}\text { Cases } \\
\text { included in } \\
\text { analysis, } \mathrm{n}\end{array}$ \\
\hline CEFK & $\begin{array}{l}200 \mathrm{mg} \text { of cefalexin and } 133 \mathrm{mg} \text { of kanamycin (Ubrolexin, } \\
\text { Boehringer Ingelheim, Ingelheim, Germany) }\end{array}$ & $2 \times$ & After milking with 24 -h interval & 236 \\
\hline CEFP & $\begin{array}{l}100 \mathrm{mg} \text { of cefoperazone (Peracef, Pfizer GmbH, } \\
\text { Karlsruhe, Germany) }\end{array}$ & $2 \times$ & After milking with 24 -h interval & 111 \\
\hline CEFQ & $\begin{array}{l}75 \mathrm{mg} \text { of cefquinome (Cephaguard LC, Intervet Ltd., } \\
\text { Milton Keynes, UK) }\end{array}$ & $3 \times$ & After 3 consecutive milkings at 12 -h interval & 144 \\
\hline
\end{tabular}

${ }^{1}$ The treatment regimens outlined above reflect those recommended by the manufacturers.

available presentation. Treatments were allocated using case numbers and randomly allocated treatment packs. The intramammary treatments were aseptically administered, via the streak canal, according to the manufacturer's recommendations as outlined below and summarized in Table 1. Group CEFK in studies $\mathrm{A}$ and $\mathrm{B}$ received the same treatment; this consisted of 2 intramammary infusions of a combination of $200 \mathrm{mg}$ of cefalexin and $133 \mathrm{mg}$ of kanamycin sulfate, equivalent to 100,000 IU (Ubrolexin, Boehringer Ingelheim Animal Health), into the infected quarter after milking, separated by an interval of $24 \mathrm{~h}$. Group CEFP in study $B$ received an intramammary infusion of $100 \mathrm{mg}$ of cefoperazone (Peracef, Pfizer $\mathrm{GmbH}$ ) into the infected quarter after milking on 2 occasions, separated by an interval of $24 \mathrm{~h}$. Finally, group CEFQ in study A was treated by infusion of $75 \mathrm{mg}$ of cefquinome (Cephaguard LC Intramammary, Intervet UK Ltd.) into the infected quarter every $12 \mathrm{~h}$ after each of 3 successive milkings.

\section{Milk Sampling and Laboratory Procedures}

Aseptic quarter milk samples were collected on $\mathrm{d}$ $0,16( \pm 1)$, and $25( \pm 1)$ for bacteriological analysis. An additional quarter sample was collected into pots containing $8 \mathrm{mg}$ of bronopol and $0.3 \mathrm{mg}$ of natamycin (Broad Spectrum Microtabs, D\&F Control Systems Inc., Dublin, CA) for SCC assessment on d $25( \pm 1)$. All samples were maintained between 2 and $8^{\circ} \mathrm{C}$ and were transported to Gloucester Laboratories (Gloucester, UK) and Global Laboratories (Mirfield, UK) for bacteriological and SCC analysis, respectively.

Bacteriology was conducted using recognized techniques, and organisms were identified and quantified using standard laboratory techniques (Quinn et al., 1994; National Mastitis Council, 1999). Bacterial isolation was directed toward the identification of Staphylococcus aureus, Streptococcus agalactiae, Streptococcus dysgalactiae, Streptococcus uberis, Escherichia coli, other coliform pathogens, Arcanobacterium pyogenes, Enterococcus spp., and CNS species. Isolation of any of the above pathogens was considered an IMI. Samples from which more than 2 bacterial species were isolated were considered contaminated. Samples not yielding any of the above pathogens were recorded as yielding no significant growth. Somatic cell counts were analyzed using the Fossomatic method (Fossomatic 400 series, Foss Electric, Hillerød, Denmark).

\section{Study Outcomes}

Treatment outcomes were assessed in several ways. Apparent bacteriological cure of a pathogen identified on d 0 was defined as having occurred when the same pathogen was not identified in either of the posttreatment samples collected on d $16 \pm 1$, d $25 \pm 1$, or both. Apparent new IMI were identified when a pathogen not present on d 0 was found to be present in either of the posttreatment samples. Finally, an outcome of "posttreatment no growth" was defined for quarters that were free of any mastitis pathogen in either of the posttreatment samples. Posttreatment quarter SCC were also assessed, both with respect to the geometric mean for each treatment group and the proportion of quarters having an SCC of less than 100,000 cells/mL posttreatment.

\section{Statistical Analyses}

Data were collated and analyzed using Microsoft Access and Excel (Microsoft Corp., Redmond, WA), Minitab (Minitab Inc., State College, PA), MLWiN (Rasbash et al., 2005), and WinBUGS (Spiegelhalter et al., 2004). Univariable analysis was conducted using the chi-squared test and ANOVA, as appropriate. Allowances were made using a layered Bonferroni correction when making multiple comparisons.

Multilevel (random effects) models (Goldstein, 1995) were specified so that correlations within the data (cows within farms) were accounted for appropriately. Model specifications took the general form

$$
\text { Pathogen free } \mathrm{ij}_{\mathrm{j}} \sim \text { Bernoulli (probability }=\pi_{\mathrm{ij}} \text { ), }
$$




$$
\begin{gathered}
\operatorname{Logit}\left(\pi_{\mathrm{ij}}\right)=\alpha+\beta_{1} \mathbf{X}_{\mathrm{ij}}^{1}+\beta_{2} \mathbf{X}_{\mathbf{j}}^{2}+\mathrm{u}_{\mathrm{j}}, \text { and } \\
\mathrm{u}_{\mathrm{j}} \sim \mathrm{N}\left(0, \sigma_{\mathrm{u}}^{2}\right),
\end{gathered}
$$

where the subscripts $\mathrm{i}$ and $\mathrm{j}$ denote the ith cow and the $\mathbf{j t h}$ farm, respectively, $\alpha$ is the regression intercept, $\mathbf{X}_{\mathbf{i j}}^{\mathbf{1}}$ is the vector of covariates at the cow level, $\beta_{1}$ are the coefficients for covariates $\mathbf{X}_{\mathbf{i j}}^{1}, \mathbf{X}_{\mathbf{j}}^{\mathbf{2}}$ is the vector of farm level covariates, $\beta_{2}$ are the coefficients for covariates $\mathbf{X}_{\mathbf{j}}^{2}$, and $u_{j}$ is the random effect to reflect residual variation between farms, to account for unobserved farm factors (normal distribution, variance $\sigma_{u}^{2}$ ). The outcome variable was a cow being pathogen free (yes $=1$, no $=0$ ) in both milk samples on d 16 and 25 after treatment in the quarter identified with clinical mastitis.

Two models were built and explored. Model 1 incorporated only information that was available at the time of treatment of each cow, and model 2 included all information collected during the research, including the pathogen(s) associated with clinical mastitis and the posttreatment cow SCC.

The distributions of covariates were assessed and transformations or recategorizations were carried out as deemed appropriate. Initial covariate investigation was conducted using MLwiN with penalized quasilikelihood for parameter estimation (Rasbash et al., 2005). To avoid the potential biased estimates that can arise from quasi-likelihood methods with binary data (Browne and Draper, 2006), final models were selected and parameters were estimated in a Bayesian framework, using Markov chain Monte Carlo (MCMC) methods in WinBUGS (Spiegelhalter et al., 2004). Diffuse flat Gaussian priors were specified $($ mean $=0$, variance $=$ $10,000)$ for the model intercept values and fixed effect coefficients. Alternative priors for the distributions of $u_{j}$ were investigated [uniform $(0,2)$ or uniform $(0,5)$ for the standard deviations or gamma $(0.001,0.001)$ for the precision (1/variance)], but the choice had little effect on the model fixed effects, and the gamma prior was used in the final models.

The MCMC analyses reported in this paper used a burn-in of at least 2,000 iterations, during which time model convergence had occurred. Parameter estimates were based on a minimum of 10,000 further iterations. Covariates remained in the model when the $95 \%$ credibility intervals for the odds ratios did not include 1.00 . Interactions between significant covariates were tested and included when the $95 \%$ credibility intervals for the odds ratio of the interaction term did not include 1.00. Further details of MCMC modeling (Gilks et al., 1996) and methods adopted for this research (Green et al., 2004) have been described previously.
To assess model fit and clinical usefulness, posterior predictions were made for the probability of cows being pathogen free after treatment (Gelman et al., 1996). The method used was based on the approach proposed by Marshall and Spiegelhalter (2003), termed a mixed prediction, and has also been reported in the context of differential gene expression (Lewin et al., 2006). The mixed prediction incorporates simulated random effects, generated from the estimated model distribution, rather than random effects, estimated directly from the data (the full predictive distribution). Therefore, the predicted data have reduced dependence on the observed data and are a better approximation of cross-validatory predictions (Marshall and Spiegelhalter, 2003). An advantage of the mixed prediction in the context of this research is that the background influence of cure rate on each farm is not assumed to be known (but fits an assumed distribution), and this is more realistic in terms of predicting the outcome of treatments of cows on future unknown farms. The method can be summarized as

Predicted pathogen free $\mathrm{ij}_{\mathrm{ij}}(1$ or 0$) \sim$ Bernoulli probability $\left(\mathrm{P}_{\mathrm{ij}}\right)$,

$$
\begin{gathered}
\text { Predicted logit }\left(\mathrm{P}_{\mathrm{ij}}\right)=\alpha+\beta_{1} \mathbf{X}_{\mathrm{ij}}^{1}+\beta_{2} \mathbf{X}_{\mathbf{j}}^{2}+\mathrm{u}_{\mathrm{j}}^{(\mathrm{sim})} \text {, and } \\
\mathrm{u}_{\mathrm{j}}^{(\text {sim })} \sim \mathrm{N}\left(0, \sigma_{\mathrm{u}}^{2}\right),
\end{gathered}
$$

where $u_{j}^{(\operatorname{sim})}$ is a random effect drawn from the distribution $\mathrm{N}\left(0, \sigma_{\mathrm{u}}^{2}\right)$ at each iteration of the MCMC procedure and other model components are described earlier. The probability of becoming pathogen free was estimated, after model convergence, for groups of cows with specified SCC levels, rectal temperatures, and pathogen statuses.

\section{RESULTS}

Sufficient data, to allow an assessment of treatment outcome, were available from 491 cases that were included in the analysis: 236, 111, and 144 cases from groups CEFK, CEFP, and CEFQ, respectively. The key pretreatment indices of cows included in the analysis are summarized in Table 2. The treated animals represented a diverse population, representing 11 different dairy breeds (with Holstein-Friesians predominating) and a wide range of parities $[$ mean $=3$ (range 1 to 10)], stages of lactation [mean $=144$ DIM (range 6 to 773 )], and yields $[$ mean $=26.4 \mathrm{~L}$ (range 6.5 to 50 )]. Individual cow SCC varied significantly in the month before treatment, from $1 \times 10^{3}$ to $7,679 \times 10^{3}$ cells $/ \mathrm{mL}$. Of the 
Table 2. Summary of key indices from cows included in the analysis

\begin{tabular}{lccrrr}
\hline Variable & $\mathrm{n}$ & Minimum & Maximum & Mean $^{1}$ & Median \\
\hline Parity & 491 & 1 & 10 & 3.12 & 3 \\
DIM & 490 & 6 & 773 & 144 & 119 \\
Milk yield (L) & 490 & 6.5 & 50 & 26.4 & 26 \\
Individual cow SCC 3 mo before treatment $\left(\times 10^{3}\right.$ cells $\left./ \mathrm{mL}\right)$ & 248 & 7 & 4,460 & 166 & 171 \\
Individual cow SCC 2 mo before treatment $\left(\times 10^{3}\right.$ cells $\left./ \mathrm{mL}\right)$ & 287 & 7 & 9,000 & 193 & 189 \\
Individual cow SCC 1 mo before treatment $\left(\times 10^{3}\right.$ cells $\left./ \mathrm{mL}\right)$ & 306 & 1 & 7,679 & 235 & 223 \\
\hline
\end{tabular}

${ }^{1}$ Geometric mean calculated for SCC data.

447 cases in which the cow had a history of previous mastitis, $71.6 \%$ occurred in quarters not previously affected by clinical mastitis in the lactation of interest; in $2.5 \%$ of cases, the same quarter had experienced clinical mastitis earlier in the same lactation. A total of $50.5 \%$ of cases occurred in animals that were housed, with the remaining cases occurring in animals at pasture.

Clinical variables at the time of presentation were also diverse and are summarized in Table 3. Rectal temperature was elevated in $13 \%$ of cases and depressed in $42 \%$, whereas appetite was depressed in only $5 \%$ of cases. The appearance of the milk was described as abnormal in $97 \%$ of cases and was defined as grossly abnormal in $8 \%$, with $25 \%$ of cases demonstrating moderate or severe signs of udder inflammation.

The etiology of the clinical mastitis cases was diverse, encompassing both "contagious" and "environmental" gram-positive and gram-negative organisms. The etiology of cases varied across the countries included in the study, with contagious pathogens being most prevalent in Germany. The etiology of cases is summarized by country of origin in Table 4 . Overall, $25.4 \%$ of cases were attributed to coliform organisms and $28.3 \%$ to Strep. uberis, whereas Staph. aureus was implicated in only $12.2 \%$ of cases. Coagulase-negative staphylococci were implicated in $13.4 \%$ of cases.

Univariable analysis failed to reveal any significant differences in the apparent cure rates or apparent new infection rates, for any of the reported bacterial species, between any of the treatment products, with the exception of the rate of apparent new infections caused by coliforms other than $E$. coli, which was significantly lower in the CEFQ group than in either of the other treatment groups $(P<0.05)$. The apparent cure and new infection rates are summarized in Tables 5 and 6 , respectively. Successful treatment outcomes, as measured by being pathogen free posttreatment, are summarized in Table 7 . When comparing treatment groups using this outcome, a significant difference was identified, with both the CEFK and CEFQ groups being significantly more likely to be pathogen free posttreatment than the CEFP group $(P<0.05)$

Results from model 1 are provided in Table 8. Cows in group CEFP were significantly less likely to be pathogen free posttreatment than quarters in treatment group CEFK [odds ratio (OR) $0.37 ; 95 \%$ credibility interval 0.16 to 0.85]. Significant differences were also detected between countries in the odds of a quarter being pathogen free posttreatment, with quarters of cows in Germany being significantly less likely to experience a successful outcome compared with quarters of cows in the United Kingdom (OR $0.25 ; 95 \%$ credibility interval 0.10 to 0.61 ). No herd-level management factors or BMSCC were found to be influential in determining the likelihood of treatment outcome. No cow-level variables were influential in the final model, with the

Table 3. Summary of key clinical variables from cows included in the analysis

\begin{tabular}{|c|c|c|c|c|}
\hline Variable & Minimum & Maximum & Mean $^{1}$ & Median \\
\hline $\begin{array}{l}\text { Udder inflammation } \\
\text { Proportion }\end{array}$ & $\begin{array}{r}\text { None } \\
0.09\end{array}$ & $\begin{array}{r}\text { Mild } \\
0.67\end{array}$ & $\begin{array}{c}\text { Moderate } \\
0.22\end{array}$ & $\begin{array}{r}\text { Severe } \\
0.03\end{array}$ \\
\hline $\begin{array}{l}\text { Appetite } \\
\text { Proportion }\end{array}$ & \multicolumn{2}{|c|}{$\begin{array}{c}\text { Normal } \\
0.95\end{array}$} & \multicolumn{2}{|c|}{$\begin{array}{l}\text { Depressed } \\
0.05\end{array}$} \\
\hline
\end{tabular}

${ }^{1} \mathrm{n}=491$. 
Table 4. Summary of etiology of clinical mastitis cases by country

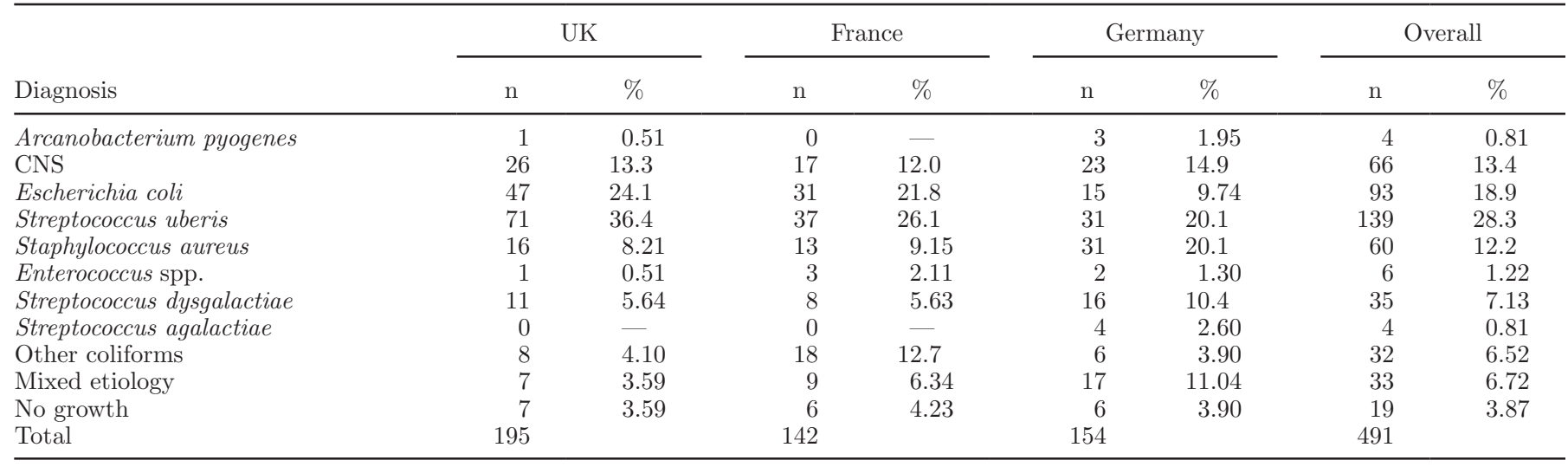

exception of individual cow SCC in the month before the clinical case and rectal temperature. Each unit rise in $\operatorname{logSCC}$ resulted in reduced odds of being pathogen free posttreatment (OR 0.77; 95\% credibility interval 0.63 to 0.94). Cows experiencing an elevated rectal temperature $\left(>39.1^{\circ} \mathrm{C}\right)$ were more likely to be pathogen free posttreatment than cows with a normal rectal temperature $\left(38.6\right.$ to $39.1^{\circ} \mathrm{C}$; OR $2.46 ; 95 \%$ credibility interval 1.05 to 5.78).

Posterior predictions from model 1 are illustrated in Figures 1, 2, and 3. The mean predicted probability of being pathogen free after treatment was 0.40 for cows with an SCC before treatment of $<200,000$ cells/ $\mathrm{mL}$, with a $95 \%$ credible interval of 0.29 to 0.50 . This probability decreased to 0.27 and 0.22 for cows with an SCC before treatment of 200,000 to 800,000 cells/ $\mathrm{mL}$ and $>800,000$ cells $/ \mathrm{mL}$, respectively. When cows were grouped according to temperature, although the uncertainty of predictions increased because smaller numbers of cows were included in each category, cows with a temperature $>39.1^{\circ} \mathrm{C}$ and a pretreatment SCC $\geq 200,000$ cells $/ \mathrm{mL}$ were more likely to become pathogen free after treatment than cows with a temperature of $\leq 39.1^{\circ} \mathrm{C}$, irrespective of pretreatment $\mathrm{SCC}$ value. Figure 3 illustrates the degree of variation seen in the data while clearly demonstrating the dramatic impact of elevated rectal temperature on the likelihood of being pathogen free posttreatment.

Results from model 2 are presented in Table 9. This model included pretreatment bacteriological status and posttreatment quarter SCC. Staphylococcus aureus was the only pathogen, when identified in the pretreatment sample, that had a significant impact on the outcome, with Staph. aureus cases being significantly less likely to be pathogen free posttreatment than other pathogens (OR 0.30; $95 \%$ credibility interval 0.10 to 0.94 ). Posttreatment quarter SCC was found to be a useful indicator of a successful outcome, with each unit increase in posttreatment quarter $\log \mathrm{SCC}$ resulting in a reduction in the odds of being pathogen free posttreatment (OR $0.76 ; 95 \%$ credibility interval 0.63 to 0.93 ). With respect to other covariates, as in model 1 , treatment group, country of origin, individual cow SCC in the month before treatment, and rectal temperature all had a significant impact on the likelihood of being pathogen free posttreatment. In addition, quarters developing a clinical case in the winter months were significantly more likely to be pathogen free than those affected in the spring (OR 4.29; 95\% credibility interval 1.19 to 15.47). As in the earlier model, none of the other cow-level variables and none of the measured farm-level variables had a significant effect on the likelihood of being pathogen free posttreatment.

Posterior predictions from model 2 are illustrated in Figures 4 and 5 . The predicted probability of being pathogen free decreased in cows with a cell count of $>200,000$ cells $/ \mathrm{mL}$ at the first cow SCC immediately after the clinical case, with the mean falling from more than 0.50 to below 0.30, as illustrated in Figure 4 . When the presence or absence of Staph. aureus in the pretreatment sample was also included, the predicted probability of being pathogen free was seen to vary with both variables (Figure 5). A cow with a posttreatment SCC of $<400,000$ cells $/ \mathrm{mL}$ and without Staph. aureus cultured in the pretreatment sample had a mean predicted probability of being pathogen free of 0.52 , whereas a cow with a posttreatment SCC of $\geq 400,000$ cells/mL and with Staph. aureus cultured in the pretreatment sample had a predicted probability of being pathogen free of 0.14 .

For each of the posterior predictions, the mean predicted probability was generally close to the observed data, suggesting good model fit. The uncertainty associated with model predictions reflected uncertainty in model parameter estimates and the limited number of cows in some of the specified categories. 
Table 5. Summary of apparent cure rates ${ }^{1}$ by treatment group

\begin{tabular}{|c|c|c|c|c|c|c|c|c|c|c|c|c|}
\hline \multirow[b]{2}{*}{ Diagnosis } & \multicolumn{3}{|c|}{ Cefalexin + kanamycin (CEFK) } & \multicolumn{3}{|c|}{ Cefquinome (CEFQ) } & \multicolumn{3}{|c|}{ Cefoperazone (CEFP) } & \multicolumn{3}{|c|}{ Overall } \\
\hline & Infected, $\mathrm{n}$ & Cured, n & Cured, \% & Infected, $\mathrm{n}$ & Cured, n & Cured, \% & Infected, $\mathrm{n}$ & Cured, $\mathrm{n}$ & Cured, \% & Infected, $\mathrm{n}$ & Cured, $\mathrm{n}$ & Cured, $\%$ \\
\hline Arcanobacterium pyogenes & 2 & 2 & 100 & 1 & 1 & 100 & 2 & 2 & 100 & 5 & 5 & 100 \\
\hline CNS & 33 & 17 & 51.5 & 24 & 12 & 50.0 & 23 & 6 & 26.1 & 80 & 35 & 43.8 \\
\hline Escherichia coli & 45 & 42 & 93.3 & 38 & 38 & 100 & 20 & 16 & 80.0 & 103 & 96 & 93.2 \\
\hline Streptococcus uberis & 70 & 45 & 64.3 & 54 & 38 & 70.4 & 36 & 24 & 66.7 & 160 & 107 & 66.9 \\
\hline Staphylococcus aureus & 38 & 14 & 36.8 & 13 & 2 & 15.4 & 18 & 6 & 33.3 & 69 & 22 & 31.9 \\
\hline Enterococcus spp. & 8 & 6 & 75.0 & 1 & 0 & - & 4 & 1 & 25.0 & 13 & 7 & 53.8 \\
\hline Streptococcus dysgalactiae & 29 & 20 & 69.0 & 6 & 6 & 100 & 9 & 7 & 77.8 & 44 & 33 & 75.0 \\
\hline Streptococcus agalactiae & 1 & 1 & 100 & 0 & 0 & - & 3 & 3 & 100 & 4 & 4 & 100 \\
\hline Other coliforms & 16 & 10 & 62.5 & 12 & 11 & 91.7 & 6 & 5 & 83.3 & 34 & 26 & 76.5 \\
\hline
\end{tabular}

${ }^{1}$ Apparent cure rates are defined on a pathogen-specific basis, reporting the proportion of quarters from which the pathogen identified pretreatment was not recovered from either of the posttreatment samples.

Table 6. Summary of apparent new infection rates $^{1}$ by treatment group

\begin{tabular}{|c|c|c|c|c|c|c|c|c|c|c|c|c|}
\hline \multirow[b]{2}{*}{ Diagnosis } & \multicolumn{3}{|c|}{ Cefalexin + kanamycin $(\mathrm{CEFK})$} & \multicolumn{4}{|c|}{ Cefquinome (CEFQ) } & \multicolumn{2}{|c|}{ Cefoperazone (CEFP) } & \multicolumn{3}{|c|}{ Overall } \\
\hline & $\begin{array}{c}\text { Uninfected, } \\
\mathrm{n}\end{array}$ & $\begin{array}{l}\text { New } \\
\text { IMI, n }\end{array}$ & $\begin{array}{l}\text { New } \\
\text { IMI, \% }\end{array}$ & $\begin{array}{c}\text { Uninfected, } \\
\mathrm{n}\end{array}$ & $\begin{array}{l}\text { New } \\
\text { IMI, n }\end{array}$ & $\begin{array}{l}\text { New } \\
\text { IMI, n }\end{array}$ & $\begin{array}{c}\text { Uninfected, } \\
\mathrm{n}\end{array}$ & $\begin{array}{l}\text { New } \\
\text { IMI, n }\end{array}$ & $\begin{array}{l}\text { New } \\
\text { IMI, \% }\end{array}$ & $\begin{array}{c}\text { Uninfected, } \\
\mathrm{n}\end{array}$ & $\begin{array}{l}\text { New } \\
\text { IMI, n }\end{array}$ & $\begin{array}{l}\text { New } \\
\text { IMI, \% }\end{array}$ \\
\hline Arcanobacterium pyogenes & 234 & 0 & - & 143 & 0 & - & 109 & 0 & - & 486 & 0 & - \\
\hline CNS & 203 & 40 & 19.7 & 120 & 22 & 18.3 & 88 & 29 & 33.0 & 411 & 91 & 22.1 \\
\hline Escherichia coli & 191 & 4 & 2.09 & 106 & 3 & 2.83 & 91 & 3 & 3.30 & 388 & 10 & 2.58 \\
\hline Streptococcus uberis & 166 & 10 & 6.02 & 90 & 4 & 4.44 & 75 & 5 & 6.67 & 331 & 19 & 5.74 \\
\hline Staphylococcus aureus & 198 & 5 & 2.53 & 131 & 7 & 5.34 & 93 & 3 & 3.23 & 422 & 15 & 3.55 \\
\hline Enterococcus spp. & 228 & 16 & 7.02 & 143 & 10 & 6.99 & 107 & 16 & 14.95 & 478 & 42 & 8.79 \\
\hline Streptococcus dysgalactiae & 207 & 2 & 0.97 & 138 & 0 & - & 102 & 1 & 0.98 & 447 & 3 & 0.67 \\
\hline Streptococcus agalactiae & 235 & 0 & - & 144 & 0 & - & 108 & 0 & - & 487 & 0 & - \\
\hline Other coliforms & 220 & 13 & 5.91 & 132 & 4 & 3.03 & 105 & 15 & 14.29 & 457 & 32 & 7.00 \\
\hline Yeast spp. & 236 & 0 & - & 144 & 1 & 0.69 & 111 & 1 & 0.90 & 491 & 2 & 0.41 \\
\hline
\end{tabular}

${ }^{1}$ Apparent new infection rates are defined on a pathogen-specific basis, reporting the proportion of quarters from which the pathogen was identified posttreatment when that pathogen had not been isolated from that quarter in the pretreatment sample. 
Table 7. Summary of successful treatment outcomes as defined by pathogen free status posttreatment in each of the treatment groups

\begin{tabular}{lccc}
\hline Item & $\begin{array}{c}\text { Cefalexin }+ \\
\text { kanamycin (CEFK) }\end{array}$ & $\begin{array}{c}\text { Cefquinome } \\
(\text { CEFQ) }\end{array}$ & $\begin{array}{c}\text { Cefoperazone } \\
(\text { CEFP) }\end{array}$ \\
\hline $\mathrm{n}$ & 236 & 144 & 111 \\
Infected posttreatment, $\mathrm{n}$ & 148 & 89 & 87 \\
Pathogen free posttreatment, $\mathrm{n}$ & 88 & 55 & 24 \\
Pathogen free posttreatment, $\%$ & $37.3^{\mathrm{a}}$ & $38.2^{\mathrm{a}}$ & $21.6^{\mathrm{b}}$ \\
\hline
\end{tabular}

${ }^{\mathrm{a}, \mathrm{b}}$ Superscripts within rows differ $(P<0.05)$.

\section{DISCUSSION}

Several interesting findings have arisen from this analysis, not the least of which is the marked difference in the etiology and outcomes of treatment of clinical cases in the different countries. It is beyond the scope of this paper to speculate on the likely reason for these differences, but this finding clearly demonstrates the importance of collecting local data and conducting international studies when studying the efficacy of new products and treatment regimens. Clearly, care should be taken when trying to extrapolate findings between different geographical areas.

In this study, we elected to look at both apparent cure rates and being pathogen free posttreatment as treatment outcomes. There were several rationales behind using freedom from a pathogen as an outcome - first, to try to take into account the impact of new IMI occurring during the study period as posttreatment outcomes were still being assessed by microbiological assessment of samples $25 \mathrm{~d}$ after treatment, and second, because of the risk of failing to identify the causal pathogen in the pretreatment sample. Importantly, being pathogen free posttreatment is clinically the most useful outcome and is also likely to be of the greatest economic value in the eyes of the producer.
There was a diverse etiology of clinical cases in the studies incorporated in this analysis, although interestingly, the only pathogen to have a significant effect on the likelihood of a successful treatment outcome was Staph. aureus. This finding supports the findings of previous research (Barkema et al., 2006) and highlights the importance of knowing the prevalence of mastitis pathogens on a unit, because this will inform treatment decisions and expectations and will allow the practitioner to be more proactive in electing for more aggressive treatment regimens in an attempt to improve treatment outcomes in herds with a high prevalence of Staph. aureus.

It is interesting to speculate on the differences between the products. As one might have expected, the fourthgeneration cephalosporin (cefquinome) performed well in the overall assessment, despite the poor cure rates against Staph. aureus reported in Table 5, highlighting the importance of multivariable analysis. Perhaps more interesting is the performance of the first-generation cephalosporin when used in combination with the aminoglycoside kanamycin. This combination was not significantly different from cefquinome and outperformed the third-generation product cefoperazone. This finding demonstrates the potential usefulness of combination intramammary antibiotic therapy.

Table 8. Summary of the model predicting the likelihood of being pathogen free posttreatment (pretreatment bacteriological status not taken into account)

\begin{tabular}{|c|c|c|c|c|c|}
\hline Covariate & Coefficient & $\mathrm{SE}$ & Odds ratio & \multicolumn{2}{|c|}{ Credibility interval } \\
\hline \multicolumn{6}{|l|}{ ref Treatment $=\mathrm{CEFK}$} \\
\hline CEFP & -0.992 & 0.412 & 0.37 & 0.16 & 0.85 \\
\hline \multicolumn{6}{|l|}{ ref StudyID $=$ B } \\
\hline $\begin{array}{l}\text { StudyID A } \\
\text { ref Country = UK }\end{array}$ & 1.023 & 0.516 & 2.78 & 0.99 & 7.81 \\
\hline France & -0.221 & 0.401 & 0.80 & 0.36 & 1.79 \\
\hline \multicolumn{6}{|l|}{ Individual Cow $\mathrm{SCC}$ in the month before treatment } \\
\hline $\begin{array}{l}\text { For each unit }(1.00) \text { rise in } \operatorname{logSCC} \\
\text { ref Rectal Temp }=38.6-39.1^{\circ} \mathrm{C}\end{array}$ & -0.265 & 0.099 & 0.77 & 0.63 & 0.94 \\
\hline Rectal Temp $<38.6^{\circ} \mathrm{C}$ & -0.265 & 0.304 & 0.77 & 0.42 & 1.41 \\
\hline Rectal Temp $>39.1^{\circ} \mathrm{C}$ & 0.901 & 0.427 & 2.46 & 1.05 & 5.78 \\
\hline
\end{tabular}




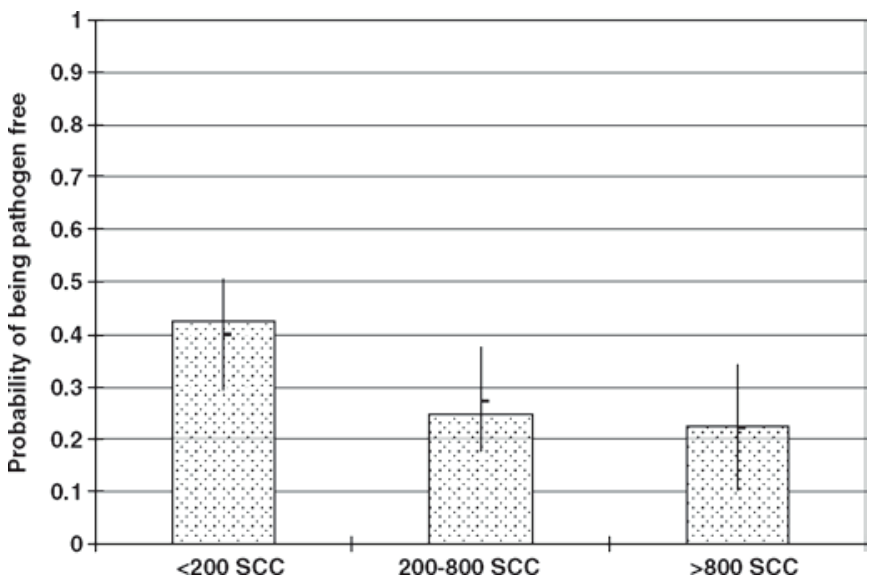

Figure 1. Illustration of the predicted probability of being pathogen free posttreatment in all cows based on the individual cow SCC in the month immediately before the occurrence of the clinical case. Bars represent the observed mean probability of cure and the lines represent the model prediction mean and $95 \%$ credible interval.

The apparent lack of similarity between our findings in this study and those of earlier researchers investigating factors affecting the likelihood of cure of subclinically affected quarters (Sol et al., 1994, 1997, 2000; Deluyker et al., 2005; Milne et al., 2005) is of interest. The apparent lack of influence of parity and herd-level variables is notable, and perhaps hard to explain. The differences identified between countries suggest that management factors may be important, although this difference could also be explained by strain differences between the countries. Unfortunately, we were unable to look at the impact of multiple infected quarters in the same cow in this study because a selection criterion was only one affected quarter per cow; it would seem likely that cows affected in multiple quarters would be less likely to cure. However, it is important to remember that clinical and subclinical mastitis are 2 very different conditions, reflected in different etiologies and typically very different chronicity of infection by the time the disease is identified. These differences alone may account for the lack of similarity between the factors affecting the likely outcome of treatment.

Some of the factors affecting the likelihood of a successful outcome are more straightforward to explain than others. The negative impact of a higher SCC pretreatment on treatment outcome could be a reflection of the duration and severity of infection; conversely, this could reflect inadequate immune cell function and thereby a need for an increased number of cells. The lack of influence of milk appearance and the level of udder inflammation are of interest because they reinforce the fact that it is not possible to reliably predict etiology cow-side in the absence of further diagnostic aids. The impact of rectal temperature, with an elevated rectal temperature being associated with an increased chance of a successful outcome, was particularly noteworthy

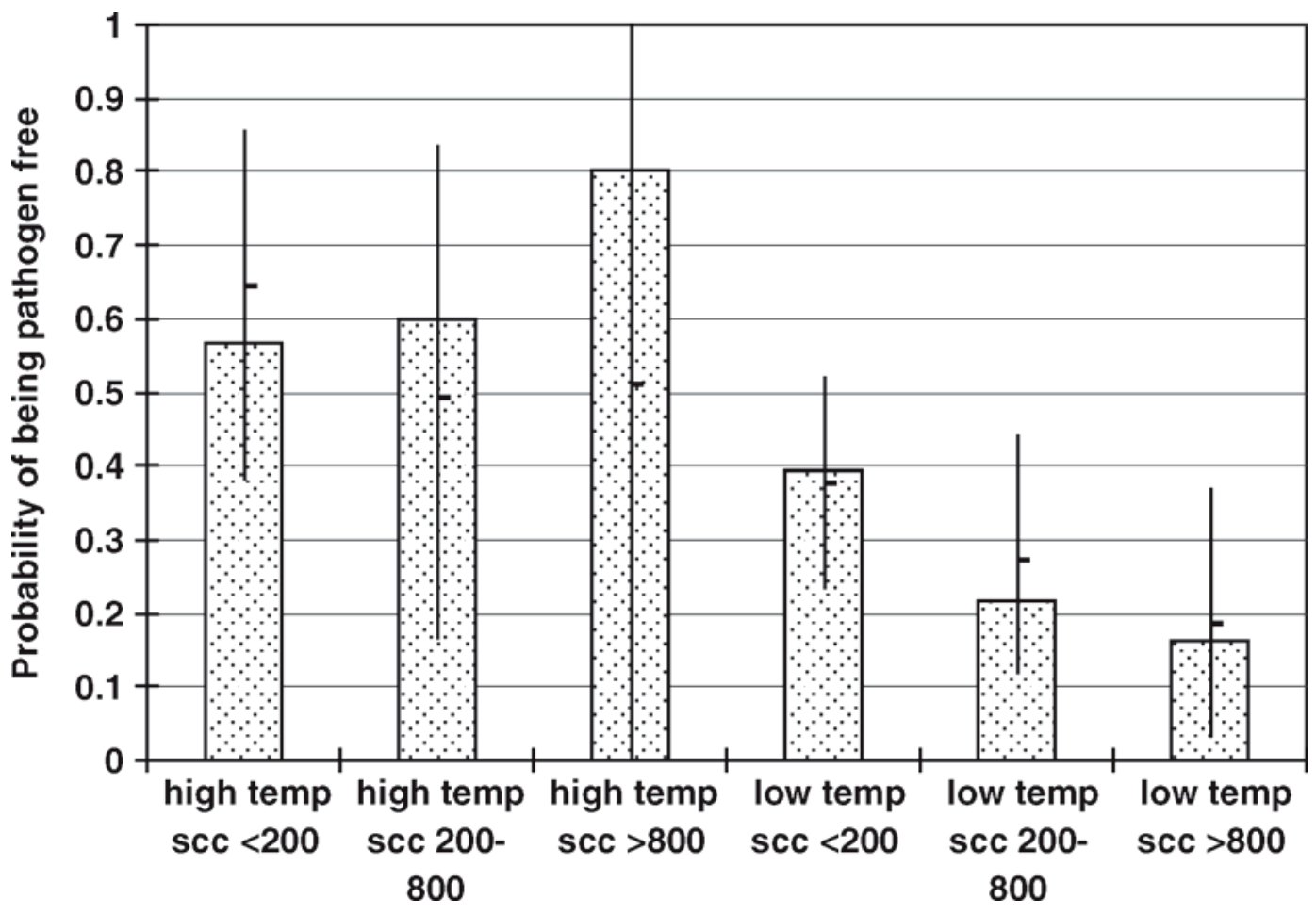

Figure 2. Illustration of the predicted probability of being pathogen free posttreatment in all cows based on the individual cow SCC in the month immediately before the occurrence of the clinical case and the presence of a temperature $>39.1^{\circ} \mathrm{C}$. 


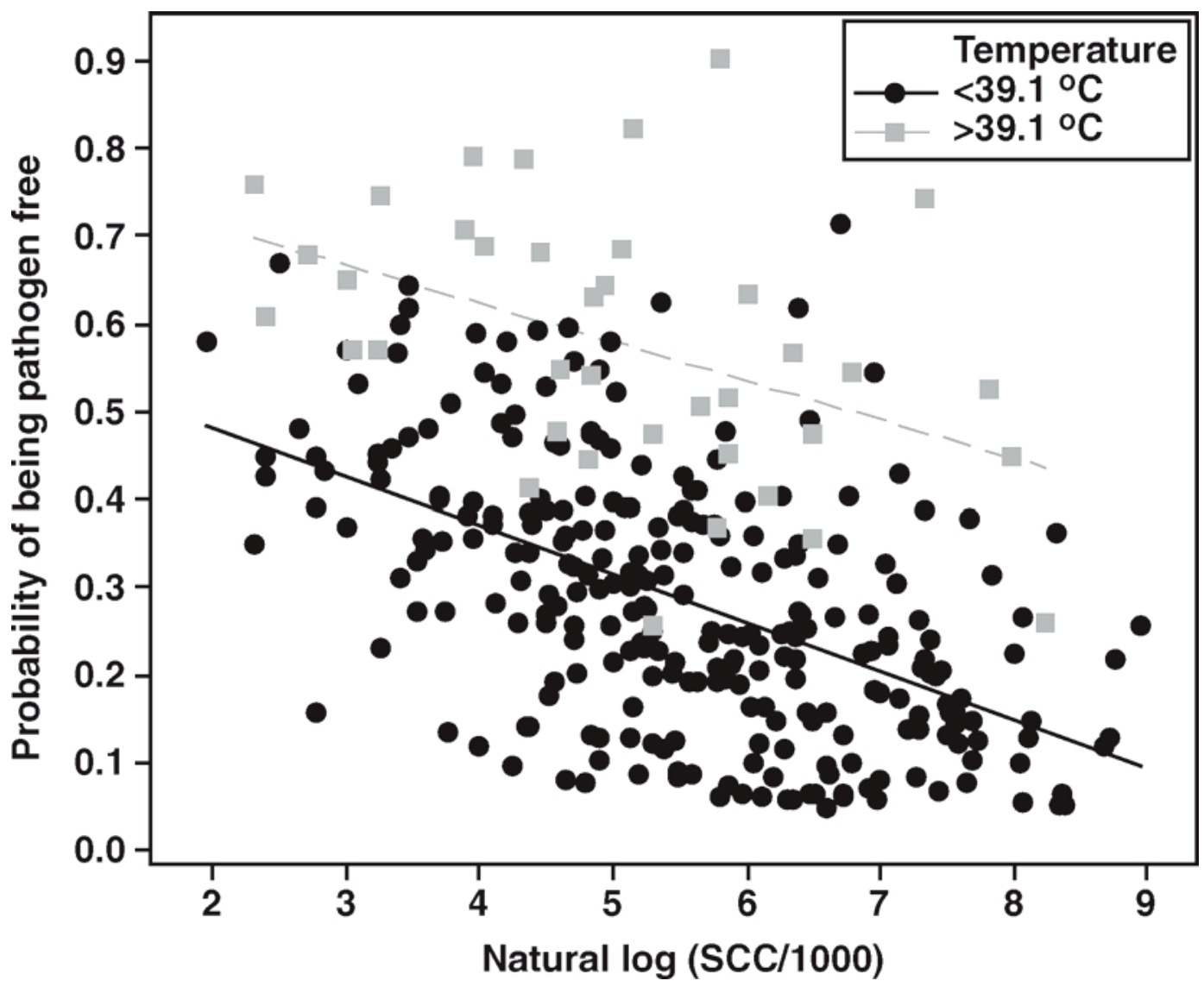

Figure 3. Scatter plot, with regression lines of best fit for each group, illustrating the predicted probability of being pathogen free posttreatment in all cows based on the individual cow SCC in the month immediately before the occurrence of the clinical case and the presence of a temperature $>39.1^{\circ} \mathrm{C}$.

and could reflect an increased likelihood of a gramnegative etiology, but could equally be an indirect indicator of a more robust immune response or of earlier detection of disease.

The influence of season is of interest, with cows affected in the winter being more than 4 times more likely to have a successful treatment outcome than animals affected in the spring. Although a host of factors could be affecting this difference, it could reflect a difference in bacterial strains or etiology, or may be a reflection of a decreased likelihood of new infection in the winter months. It is interesting that this finding concurs with a previous finding of the authors that cows experiencing a cell count increase in the summer months were less likely to return to a low SCC than cows experiencing an increase in the winter months (Green et al., 2006). In light of these findings, practitioners may want to temper their expectations or modify their clinical mastitis treatment regimens at different times of the year.

The mean rate for becoming pathogen free after treatment for clinical mastitis for all cows in the study was less than 0.40 , and the posterior predictions were aimed at investigating whether the significant factors identified would be clinically useful to differentiate the probability of becoming pathogen free (cure) for different groups of cows. Cow SCC before and after treatment was useful in predicting this outcome, with

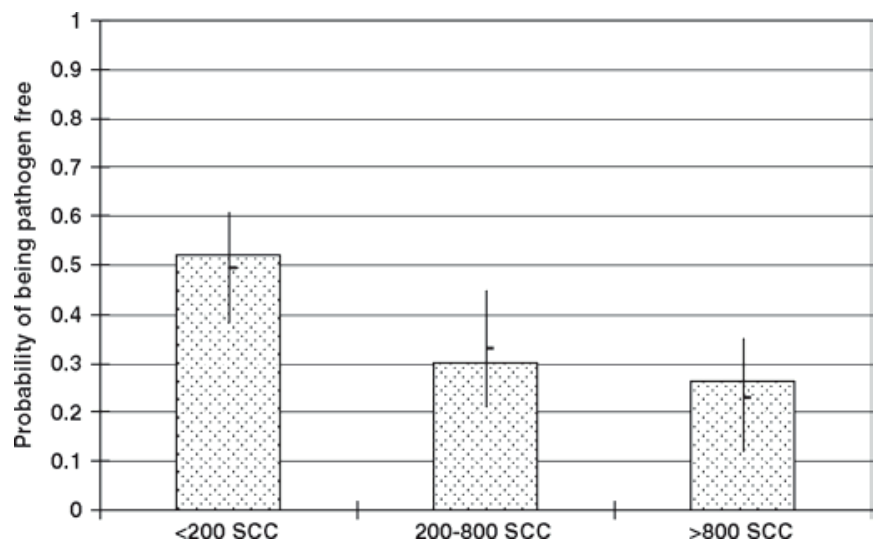

Figure 4. Illustration of the likelihood of being pathogen free posttreatment in all cows, taking into account posttreatment quarter SCC. Bars represent the observed mean probability of cure and the lines represent the model prediction mean and $95 \%$ credible interval. 
Table 9. Summary of the model investigating the likelihood of being pathogen-free posttreatment, taking into account pretreatment bacteriological status and posttreatment SCC

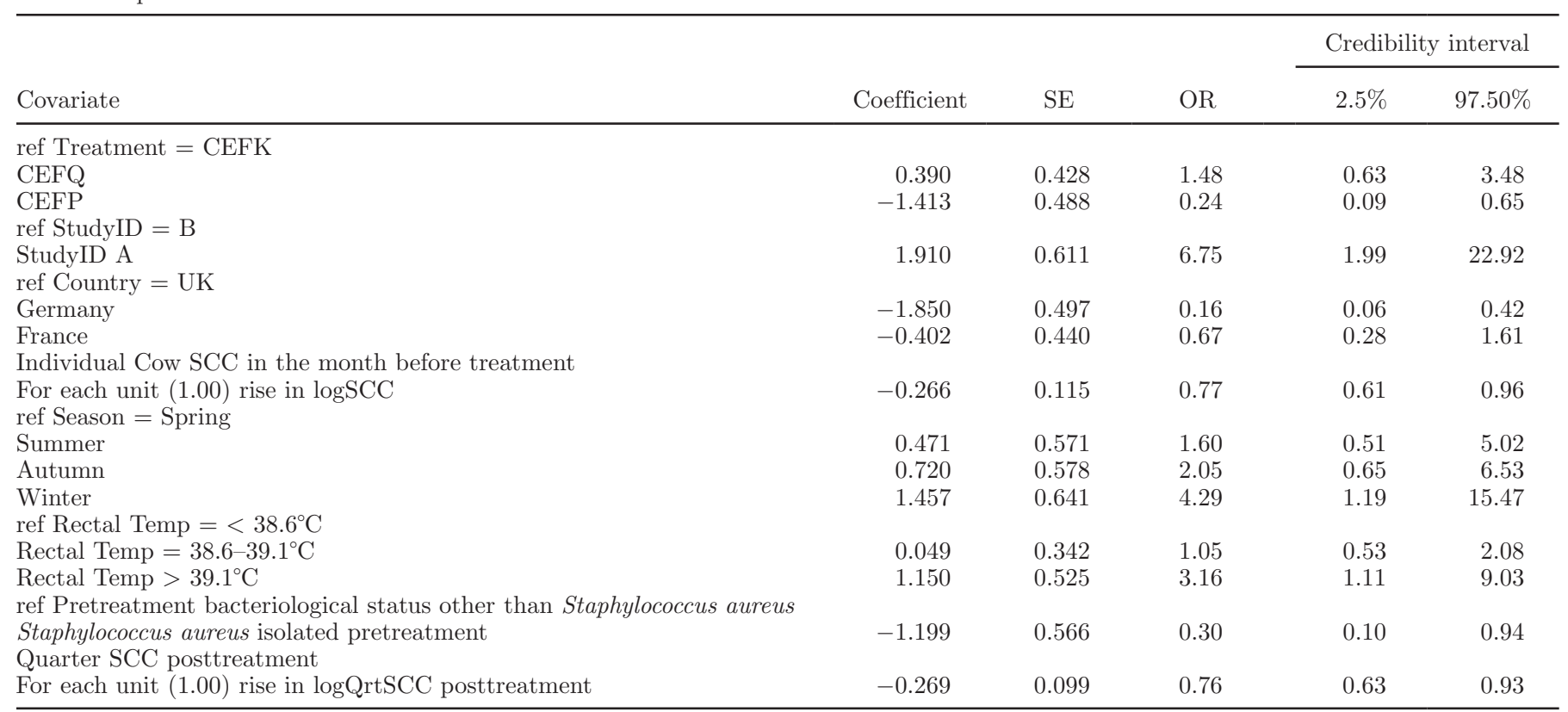

the difference between the low SCC and high SCC categories being an approximate halving in the probability of becoming pathogen free. When this was added to rectal temperature and the presence of Staph. aureus, a further discrimination was possible between cows with different attributes. However, overall a large degree of uncertainty was associated with the predicted outcomes, reflecting the variability within the data and the number of cows within different categories. Although useful determinants of a successful outcome were identified in this research, the uncertainty of predicted outcomes indicates considerable difficulty in accurately discrimi-

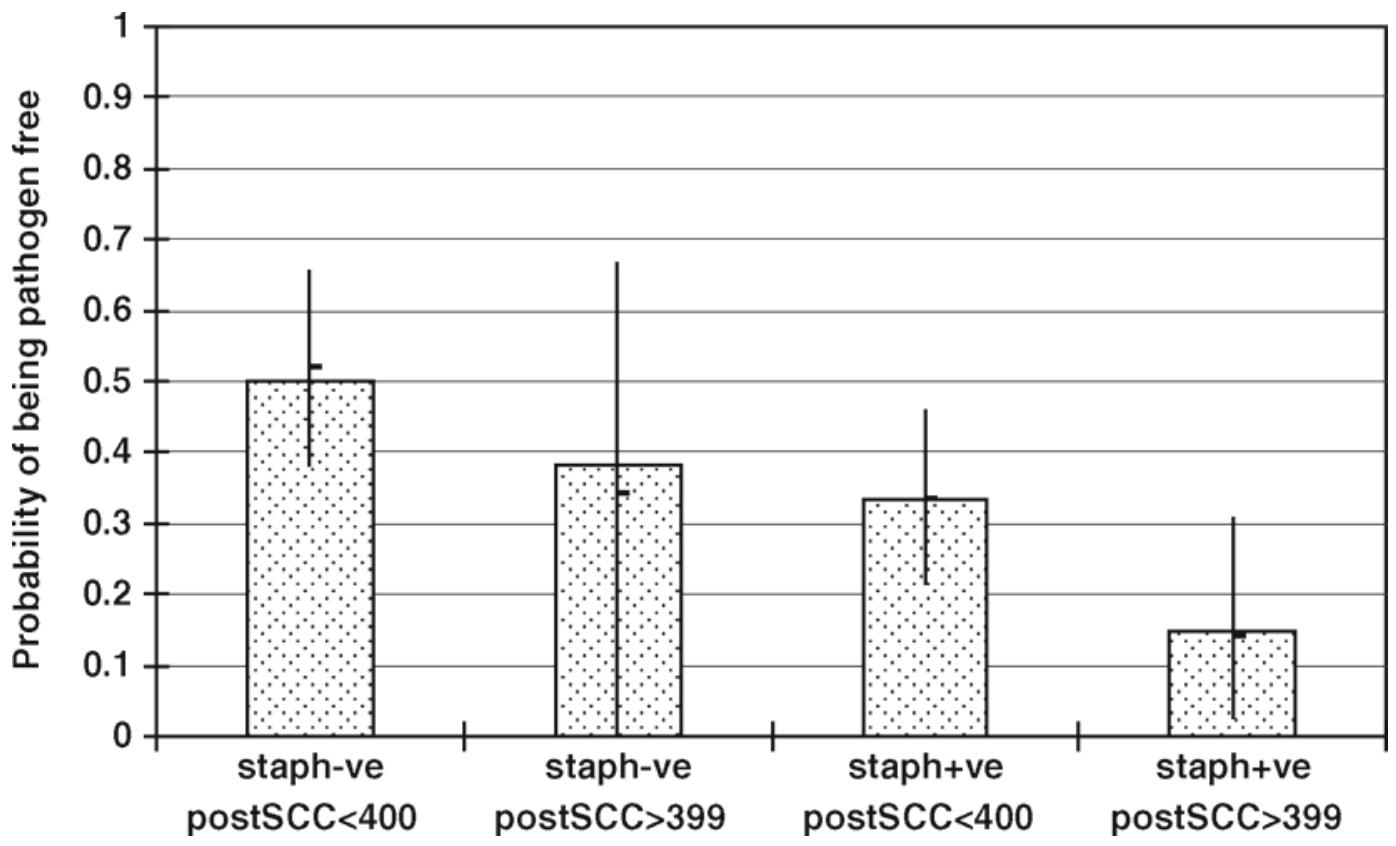

Figure 5. Illustration of the likelihood of being pathogen free posttreatment in cows infected pretreatment with Staphylococcus aureus, taking into account posttreatment quarter SCC. Bars represent the observed mean probability of cure and the lines represent the model prediction mean and $95 \%$ credible interval. 
nating individual cows that will or will not become pathogen free after treatment for clinical mastitis.

\section{CONCLUSIONS}

The impact of treatment, cow characteristics, and farm factors on the probability of a cow becoming pathogen free after cephalosporin-containing antibiotic therapy for clinical mastitis were investigated. Country, season, pretreatment rectal temperature, individual cow SCC before and after treatment, and mastitis pathogen were identified as useful predictors of a successful outcome, but parity, milk yield, herd bulk milk cell count, and other farm management factors were not.

\section{ACKNOWLEDGMENTS}

The authors acknowledge the input of the study investigators and farmers who participated in the research and, in particular, the generosity of Boehringer Ingelheim Animal Health in agreeing to share the data freely to allow the analysis presented in this paper. The research was supported by the Wellcome Trust (London, UK); Martin Green is a Wellcome Trust Clinical Fellow.

\section{REFERENCES}

Barkema, H. W., Y. H. Schukken, and R. N. Zadoks. 2006. Invited review: The role of cow, pathogen, and treatment regimen in the therapeutic success of bovine Staphylococcus aureus mastitis. J. Dairy Sci. 89:1877-1895.

Bradley, A. J., and M. J. Green. 2001a. Adaptation of Escherichia coli to the bovine mammary gland. J. Clin. Microbiol. 39:18451849.

Bradley, A. J., and M. J. Green. 2001b. Aetiology of clinical mastitis in six Somerset dairy herds. Vet. Rec. 148:683-686.

Bradley, A. J., J. N. Huxley, and M. J. Green. 2003. A rational approach to dry cow therapy II-Making logical treatment decisions. In Pract. 25:12-17.

Bradley, A. J., K. A. Leach, J. E. Breen, L. E. Green, and M. J. Green. 2007. Survey of the incidence and aetiology of mastitis on dairy farms in England and Wales. Vet. Rec. 160:253-258.

Browne, W. J., and D. Draper. 2006. A comparison of Bayesian and likelihood-based methods for fitting multilevel models. Bayesian Anal. 1:473-514.

Deluyker, H. A., S. T. Chester, and S. N. Van Oye. 1999. A multilocation clinical trial in lactating dairy cows affected with clinical mastitis to compare the efficacy of treatment with intramammary infusions of a lincomycin/neomycin combination with an ampicillin/cloxacillin combination. J. Vet. Pharmacol. Ther. 22:274-282.

Deluyker, H. A., S. N. Van Oye, and J. F. Boucher. 2005. Factors affecting cure and somatic cell count after pirlimycin treatment of subclinical mastitis in lactating cows. J. Dairy Sci. 88:604-614.

Ganiere, J. P., and L. Denuault. 2009. Synergistic interactions between cefalexin and kanamycin in Muller-Hinton broth medium and in milk. J. Appl. Microbiol. In press.

Gelman, A., X. Meng, and H. Stern. 1996. Posterior predictive assessment of model fitness via realized discrepancies. Statist. Sinica 6:733-807.

Gilks, W. R., S. Richardson, and D. J. Spiegelhalter. 1996. Markov Chain Monte Carlo in Practice. Chapman and Hall, London, UK.
Goldstein, H. 1995. Multilevel Statistical Models. 2nd ed. Edward Arnold, London, UK.

Green, M. J., A. J. Bradley, H. Newton, and W. J. Browne. 2006. Seasonal variation of bulk milk somatic cell counts in UK dairy herds: Investigations of the summer rise. Prev. Vet. Med. 74:293308.

Green, M. J., P. R. Burton, L. E. Green, Y. H. Schukken, A. J. Bradley, E. J. Peeler, and G. F. Medley. 2004. The use of Markov chain Monte Carlo for analysis of correlated binary data: patterns of somatic cells in milk and the risk of clinical mastitis in dairy cows. Prev. Vet. Med. 64:157-174.

Hillerton, J. E., and J. E. Semmens. 1999. Comparison of treatment of mastitis by oxytocin or antibiotics following detection according to changes in milk electrical conductivity prior to visible signs. J. Dairy Sci. 82:93-98.

Hornish, R. E., and S. F. Kotarski. 2002. Cephalosporins in veterinary medicine - Ceftiofur use in food animals. Curr. Top. Med. Chem. $2: 717-731$.

Lewin, A., S. Richardson, C. Marshall, A. Glazier, and T. Aitman. 2006. Bayesian modelling of differential gene expression. Biometrics $62: 1-9$.

Marshall, E. C., and D. J. Spiegelhalter. 2003. Approximate crossvalidatory predictive checks in disease mapping. Stat. Med. 22:1649-1660.

Milne, M. H., A. M. Biggs, D. C. Barrett, F. J. Young, S. Doherty, G. T. Innocent, and J. L. Fitzpatrick. 2005. Treatment of persistent intramammary infections with Streptococcus uberis in dairy cows. Vet. Rec. 157:245-250.

Monzon, M., C. Oteiza, J. Leiva, and B. Amorena. 2001. Synergy of different antibiotic combinations in biofilms of Staphylococcus epidermidis. J. Antimicrob. Chemother. 48:793-801.

National Mastitis Council. 1999. Laboratory Handbook on Bovine Mastitis. Natl. Mastitis Counc. Inc., Madison, WI

Odds, F. C. 2003. Synergy, antagonism, and what the chequerboard puts between them. J. Antimicrob. Chemother. 52:1. (Epub)

Oliver, S. P., R. A. Almeida, B. E. Gillespie, S. J. Headrick, H. H. Dowlen, D. L. Johnson, K. C. Lamar, S. T. Chester, and W. M. Moseley. 2004. Extended ceftiofur therapy for treatment of experimentally-induced Streptococcus uberis mastitis in lactating dairy cattle. J. Dairy Sci. 87:3322-3329.

Quinn, P. J., M. E. Carter, B. Markey, and G. R. Carter. 1994. Clinical Veterinary Microbiology. Wolfe, London, UK.

Rasbash, J., W. J. Browne, M. Healy, B. Cameron, and C. Charlton. 2005. MLwiN Version 2.02. Mulilevel Models Project, Institute of Education, London, UK.

Sol, J., O. C. Sampimon, H. W. Barkema, and Y. H. Schukken. 2000. Factors associated with cure after therapy of clinical mastitis caused by Staphylococcus aureus. J. Dairy Sci. 83:278-284.

Sol, J., O. C. Sampimon, J. J. Snoep, and Y. H. Schukken. 1994. Factors associated with bacteriological cure after dry cow treatment of subclinical staphylococcal mastitis with antibiotics. J. Dairy Sci. 77:75-79.

Sol, J., O. C. Sampimon, J. J. Snoep, and Y. H. Schukken. 1997. Factors associated with bacteriological cure during lactation after therapy for subclinical mastitis caused by Staphylococcus aureus. J. Dairy Sci. 80:2803-2808.

Sordillo, L. M., K. Shafer-Weaver, and D. DeRosa. 1997. Immunobiology of the mammary gland. J. Dairy Sci. 80:1851-1865.

Spiegelhalter, D. J., A. Thomas, and N. Best. 2004. WinBUGS Version 1.4.1. MRC Biostatistics Unit, Cambridge, UK.

Watts, J. L. 1988. Etiological agents of bovine mastitis. Vet. Microbiol. 16:41-66

White, M. E., L. T. Glickman, F. D. Barnespallesen, E. S. Stem, P. Dinsmore, M. S. Powers, P. Powers, M. C. Smith, and D. Jasko. 1986. Accuracy of clinician in predicting the bacterial cause of clinical bovine mastitis. Can. Vet. J. 27:218-220.

Zadoks, R. N., B. E. Gillespie, H. W. Barkema, O. C. Sampinion, S. P. Oliver, and Y. H. Schukken. 2003. Clinical, epidemiological and molecular characteristics of Streptococcus uberis infections in dairy herds. Epidemiol. Infect. 130:335-349. 